To the Editors:

\title{
Attitudes on abortion among a group of Sri Lankan medical students
}

A study on attitudes on abortion for foetal anomalies, incest and rape was conducted among a group of 100 medical students of the Faculty of Medicine, University of Colombo, who had completed the medico-legal module and the forensic medicine appointment. In spite of a restrictive law on abortion, it is estimated that 44.7 per 1000 women aged 15 to 49 years have abortions each year in Sri Lanka [1]. This is a classic case of turning a blind eye to the obvious because it is too hot to handle. As medical professionals we face the ethical dilemma of having to offer abortions for genuine reasons. It has been made easy for the doctors by law, when the mother's life is in danger. But not so with other situations like foetal anomalies, incest and rape [2].

Among the students who participated in the study, agreement that abortion should be legalized in foetal anomalies, incest and rape, was $87 \%, 78 \%$ and $77 \%$, respectively. In contrast only a minority wanted abortions legalized for cases of illegitimate relationships $(27 \%)$ and as a family planning method (19\%).

One may argue that the number of abortions done for foetal anomalies, incest and rape is small, $(0.9 \%)$ [3], but what of the rights of the few and the dilemma these situations bring to the medical professional. In many instances, medical professionals are helpless in addressing the genuine reasons for abortions due to lack of legal support. Medical professionals should ask themselves just one question. What is my advice to anybody who comes to me for advice regarding a genuine reason for abortion? Will it be to advocate an illegal abortion and to suffer with our own conscience knowing that we have done right by the patient but violated the law of the land, or will it be to tell the patients that we can't help them?

The medical students of this study have chosen to do away with the ethical dilemma. It is now the turn of the wider medical fraternity to do the same for the benefit of the public as well as the medical professionals.

\section{References}

1. Rajapaksha LC. Estimates of induced abortion in urban and rural Sri Lanka. Journal of the College of Community Physicians of Sri Lanka 2002; 7: 10-5.

2. Haniffa R. Reducing abortions is a public health issue. Ceylon Medical Journal 2003; 48: 100.

3. Perera J, De Silva T, Gange H. Knowledge, behaviour and attitudes on induced abortions and family planning among Sri Lankan women seeking termination of pregnancy. Ceylon Medical Journal 2004; 49: 14-7.

\section{K H Wickramasinghe ${ }^{1}$, S I Wickramasinghe ${ }^{1}$, K R Atukorala ${ }^{1}$ and B Weerasundera ${ }^{2}$}

${ }^{1}$ Student, Faculty of Medicine, University of Colombo, Sri Lanka.

${ }^{2}$ Department of Forensic Medicine, Faculty of Medicine, University of Colombo, Sri Lanka.

Correspondence: KHW, e-mail <kumuduwicks@yahoo.com>. Received 6 July 2008 and revised version accepted 9 October 2009. Competing interests: none declared. 